\title{
Analysis on Impact of Acid Hydrolysis on the Hydrogen Bonding Network in Cellulose to Obtain Microcrystalline Cellulose: A Statistical Approach
}

Vishnu Prabha Muthusamy (D 1601rs02@psgtech.ac.in )

PSG College of Technology https://orcid.org/0000-0002-1481-7930

Vaideki Krishnakumar

PSG College of Technology

\section{Research Article}

Keywords: Acid Hydrolysis- Optimization, Box-Behnken Design, Microcrystalline cellulose, Total Crystallinity Index, Hydrogen-Bonding Network.

Posted Date: September 17th, 2021

DOI: https://doi.org/10.21203/rs.3.rs-790401/v1

License: (c) (i) This work is licensed under a Creative Commons Attribution 4.0 International License.

Read Full License 


\section{Abstract}

Hydrolysis of a cellulose biomass results in breaking down the cellulose microfibrils into microcrystalline cellulose (MCC) or nanocrystalline cellulose (NCC) depending on the reaction conditions. Cellulose microfibrils are established robustly due to the synergistic interaction of van der Waals, inter- and intramolecular hydrogen bonds and glycosidic bond between glucan moieties of cellulose polysaccharide. The hydrogen bonding network plays a crucial role in conforming cellulose chains into crystalline and amorphous region thereby determining its degree of crystallinity. The knowledge of hydrogen bonds in cellulose hence becomes indispensable to understand the crystallinity of cellulose before and after a hydrolysis reaction. However, the nature of hydrogen bonds after hydrolysis and how they contribute to the mechanical properties of resultant MCC/NCC are yet to be realized. This paper is therefore intended to discuss the degree of crystallinity of cellulose particles obtained after hydrolyzing waste cotton fibers (WCF) in two parts: part I, obtaining MCC with maximum total crystallinity index (TCl) by acid hydrolysis of WCF using Box Behnken Design; part II, comparing degree of crystallinity of MCC sample exhibiting highest TCl with that of WCF using analytical tools like X-ray Photoelectron Spectrometer, X-ray Diffractometer and Fourier Transform Infra- Red spectrometer. The physical dimension of MCC particle with maximum $\mathrm{TCl}$ has been verified using Field Emission Scanning Electron Microscopic images.

\section{Highlights Of The Article}

- Acid hydrolysis process of waste cotton was optimized using Box Behnken Design to obtain microcrystalline cellulose (MCC).

- Extraction of mathematical model that influences the total crystallinity index of MCC.

- Comparison of hydrogen bonding network between waste cotton fibers and MCC particles.

- Influence of acid hydrolysis on lattice parameters of cotton cellulose.

\section{Introduction}

Conversion of raw cotton to fabric involves a great deal of mechanical and chemical processes wherein textile wastes are generated abundantly. These wastes are either degraded to compost or upcycled to high end ameliorated products. Many authors have reported upcycling of waste cotton leftovers to produce attractive products such as raw materials for biofuels (Chaturvedi \& Verma, 2013), microfibrillated cellulose (MFC), microcrystalline cellulose (MCC) and nanocrystalline cellulose (NCC) for filler applications (Farahbakhsh et al., 2014). Of all these applications, manipulation of MCC/NCC as fillers has attained exceptional attention due to its low cost, low health risk, biodegradability, recyclability and its function as property modifier (Ling et al., 2019)(Farahbakhsh et al., 2014). Both acid and enzymatic hydrolysis are widely used techniques to isolate MCC from raw materials, but the former technique using mineral acids is the mostly preferred method because enzymatic hydrolysis presents few obstacles such as difficulty in access to crystalline cellulose and requirement of pretreatment. The important parameters that affect the acid hydrolysis of cellulose biomass are acid concentration, 
temperature, reaction time and solid: liquid ratio (fiber $(\mathrm{g})$ : acid $(\mathrm{ml})$ ). These parameters could be optimized to achieve required properties of MCC which includes high yield, particle size, crystallinity index etc.

In order to choose MCC as a reinforcement to enhance the mechanical property of a polymer matrix, it should possess better mechanical properties. (llyas et al., 2018) has pointed out that higher crystallinity indices of the fibers result in higher tensile strength of the fibers. The main aspect that contributes to its mechanical strength and chemical inertness is the hydrogen bonding network that holds the cellulose microfibrils together. (Nelson \& O'Connor, 1964) denoted this fraction of $\mathrm{OH}$ groups which are hydrogen bonded in a regular crystalline pattern as Total Crystallinity Index (TCl). It has been proposed that the absorptivity ratio of the 1372 and $2900 \mathrm{~cm}^{-1}$ peaks derived from IR data is congruous in assessing the $\mathrm{TCl}$ of the cellulose samples. The basis for selection of these of two peaks are: $1372 \mathrm{~cm}^{-1}$ (C-H bending) is sensitive to degree of crystallinity of cellulose and insensitive to adsorbed water while the absorbance at $2900 \mathrm{~cm}^{-1}$ (C-H stretching) does not change significantly with respect to changes in the crystallinity.

A complete elucidation on crystalline faction and molecular alignment in crystalline faction along with the hydrogen bonding system of cellulose I $\beta$ (prepared from cellulosic mantles of tunicate) was given by (Nishiyama et al., 2002). The comparison between the synchrotron X-ray and neutron fiber diffraction results stated that the cellulose $I \beta$ consist of two parallel chains with slightly different conformations and arranged in "parallel up" fashion. The monoclinic unit cell parameters was recommended as follows: $a=$ $7.784 \AA, b=8.201 \AA, c$ (chain direction and unique axis) $=10.38 \AA$ and $y=96.5^{\circ}$. A detailed description of the preferred and random orientation of cellulose la and $\mid \beta$, cellulose $I$, cellulose $I I_{\mid}$and $I I_{\|}$based on simulation using Mercury 3.0 program is presented by (French, 2014). Accordingly, apart from the polymorphic nature of cellulose samples, the reflections and intensities of diffraction peaks is dependent on the sample preparation (a pressed pellet or sprinkled onto sticky tape) and sample orientation to the incident $x$-ray beams. If the cellulose $1 \beta$ crystallites are randomly oriented when they are placed in the sample holder, the shoulder peak at about $20.5^{\circ} 2 \theta$ for the (012) and (102) reflections are observed. Whereas they do not appear with crystallites having preferred orientation about the fiber axis that lie parallel to the sample surface. The moderate peak at $34.5^{\circ} 2 \theta$ is a composite of several reflections and hence (004) is not a dominant contributor to the diffraction peaks of cellulose I $\beta$. The empirical formula proposed by (Segal et al., 1959) to estimate the degree of crystallinity of native cellulose using XRD pattern is widely used wherein the crystallinity index $(\mathrm{Cl})$ is expressed as a ratio of difference between maximum diffraction intensity corresponding to (200) lattice diffraction and the intensity of diffraction at $18^{\circ} 2 \theta$ to that of maximum diffraction intensity corresponding to (200) lattice diffraction.

Cellulose polymer could be studied using XPS as the carbon atoms respond to the surrounding chemical environment by exhibiting changes in the binding energy. Though the elemental composition of cellulose is primarily carbon, oxygen hydrogen and XPS could only detect carbon and oxygen atoms until the depth between 10 and $20 \mathrm{~nm}$, it helps to achieve better insight on the effect of hydrolysis on the cotton fiber surface. In cellulose, the carbon atoms are either bonded to single oxygen atom (C-O) or to two oxygen atoms (O-C-O) and to carbon and hydrogen $(\mathrm{C}-\mathrm{H})$. These different environments are reflected as signals in 
the XPS spectra of cellulose polymer. Theoretically, the $\mathrm{O} / \mathrm{C}$ ratio of pure cellulose is found as 0.83 . Upon deconvolution, $\mathrm{C} 1 \mathrm{~s}$ signal of pure cellulose is supposed to exhibit two sub-peaks due to (i) $\mathrm{C}-\mathrm{O}$ or $\mathrm{C}-\mathrm{OH}$ from alcohol bonding and (ii) $\mathrm{O}-\mathrm{C}-\mathrm{O}$ from acetal bonding. Conversely, most cellulose exhibit an additional peak which may be due to C-C bonding from contaminants or any other impurities in the sample (Ly et al., 2008). (Fras et al., 2005) has reported that the outer laminar layers of waxes, proteins and pectin in the cotton fiber consisted of $\mathrm{C} 1$ type carbon.

Design Expert is a statistical software that offers a wide range of tools for screening, analyzing and optimizing the vital factors that affect a process. Response Surface Methodology (RSM) is a tool in Design Expert that helps to determine the ideal process settings and thus achieve optimal performance of the process. The most common methods in RSM used for optimization of a process are Box Behnken Design (BBD) and Central Composite Design (CCD). BBD has more advantages over CCD due to the following reasons: (a) less expensive as it provides minimum experimental runs with same number of factors, (b) it runs with fewer design points than CCD. Optimization of acid hydrolysis of WCF to obtain MCC particles with maximum possible TCl using BBD is a novel work. Hence, in this communication, the authors report statistical optimization of the same and the aftermath of hydrolysis on hydrogen bonding network. Since FTIR spectroscopy is a simple yet robust technique as the IR data is influenced by the background of the molecules involved in the vibration, FTIR was used to evaluate TCl. The diffraction studies were also used to reiterate the degree of crystallinity of the MCC sample with maximum TCl. The purity of the same has been validated using XPS analysis.

\section{Materials And Methods}

\subsection{Materials}

Waste cotton fibers was obtained from neighboring textile industry (Coimbatore, Tamil Nadu). Hydrochloric acid, lodine, Potassium lodide, Zinc Chloride and acetone were all laboratory grade reagents purchased from HiMedia.

\subsection{Methodology- Extraction of Cellulose Particles}

WCF was oven dried at $100^{\circ} \mathrm{C}$ for 30 mins prior to the hydrolysis and cellulose particles were extracted using hydrochloric acid based on these experimental runs provided by Box-Behnken Design. The hydrolysis process resulted in the depolymerization of the cotton fibers thereby reducing it into particles which were believed to be microcrystalline in nature. Cellulose particles were then centrifuged at 5000 rpm for 15 mins and neutralized to $\mathrm{pH} 7$ after multiple washes with double distilled water. The resulting aqueous cellulose was filtered using Whatman filter paper and oven dried at $80^{\circ} \mathrm{C}$ for 30 mins. The dry cellulose powder was stored in airtight vials and were used for further studies.

\subsection{Model Development}

Box-Behnken model from Design Expert software v7.0.0, Stat Easelnc., Minneapolis, USA was used in the present work to optimize output surface response with respect to the input reaction parameters. Four 
reaction parameters that strictly affect the acid hydrolysis process viz., acid concentration, solid: liquid ratio, temperature and reaction time was opted to optimize $\mathrm{TCl}$ of the cellulose powders. A 3-level BBD, low $(-1)$, high (+1) and mean level (0) for the input parameters are given below: Acid Concentration (AC) 2.5/5/3.75 N, solid: liquid (S:L) ratio - 1:15/1:25/1:20 (g/ml), Temperature $(\mathrm{T})-80 / 90 / 85^{\circ} \mathrm{C}$ and time (t) $-60 / 90 / 75$ mins. Combinations of experimental runs with 3 central points as suggested by the BBD model in terms of coded and actual variables are shown in Table 1.

\section{Characterizations}

Initially, WCF and all cellulose powders obtained from BBD experimental runs were subjected to ATR- FTIR analysis to evaluate TCl as proposed by (Nelson \& O'Connor, 1964) using the ratio of absorbance at 1372 and $2900 \mathrm{~cm}^{-1}$. WCF and cellulose sample that resulted in maximum $\mathrm{TCl}(\mathrm{MTCl})$ were then subjected to the following characterizations: FE-SEM, XPS and XRD. Colour identification test was also performed on $\mathrm{MTCl}$ to confirm its microcrystalline nature qualitatively.

\subsection{Field Emission Scanning Electron Microscopy}

WCF and $\mathrm{MTCl}$ were assessed using MIRA3 XMU (TESCAN) FESEM microscopy in order to understand and determine the morphology and particle size respectively. The two samples were sputtered with gold prior to observation under FESEM.

\subsection{X-Ray Photoelectron Spectrometry}

X-ray Photoelectron Spectrometry (XPS) was performed using a PHI5000 VersaProbe III spectrometer (ULVAC-PHI, Inc, USA), equipped with a monochromatic X-ray source (Al Ka, hn 1/4 $1486.6 \mathrm{eV}$ ) operating at $150 \mathrm{~W}$. During the analysis, the samples were flooded with low-energy electrons to counteract surface charging. The hydrocarbon component of the C1s peak with binding energy $285.0 \mathrm{eV}$ was used as a reference for charge correction. Survey spectra were recorded at $1 \mathrm{eV} / \mathrm{step}$ while the region spectra were taken at $0.05 \mathrm{eV} / \mathrm{step}$.

\subsection{X-Ray Diffractometry}

The X-Ray diffraction pattern for WCF and MTCl samples were acquired using Schimadzu, Japan/600 diffractometer with $\mathrm{Cu} \mathrm{Ka}(1.5406 \AA)$ as radiation source. The lattice parameters of the samples were calculated using the following equation.

$$
\frac{1}{d^{2}}=\frac{1}{\sin ^{2} \gamma} \frac{h^{2}}{a^{2}}+\frac{k^{2}}{b^{2}}+\frac{1^{2} \sin ^{2} \gamma}{c^{2}}-\frac{2 h k \cos \gamma}{a b}
$$

Where $\mathrm{d}=$ inter-planar distance

$h, k, I=$ miller index of the plane

a, b, c = lattice parameters of unit cell 
$Y=$ crystallographic angle

The crystallite size and crystallinity index percentage of the WCF and MTCI was deduced by Scherrer equation (Eq. 2) and Segal's equation (Eq. 3) respectively as given by (Nam et al., 2016).

$$
\tau=\frac{K \lambda}{\beta \cos \theta}
$$

2

Where $\tau=$ crystallite size perpendicular to the lattice plane-(2 00$)(\AA)$

$\lambda=$ wavelength of the $x$-ray used $-1.5406 \AA$

$\beta=$ full-width at half maximum of the diffraction peak (radians)

$\theta=$ diffraction angle of the peak

The Segal crystallinity index percentage of the sample

$C I=\frac{I_{t-} I_{a}}{I_{t}} \times 100(3)$

Where $\mathrm{Cl}=$ Crystallinity index of the sample

$I_{t}=$ total intensity of the $(200)$ peak at $2 \theta=22.7^{\circ}$

$\mathrm{I}_{\mathrm{a}}=$ amorphous intensity at $2 \theta=18.0^{\circ}(3)$

\subsection{ATR-Fourier Transform Infra-Red Spectroscopy}

The IR spectrum of the WCF and MTCI was obtained using Perkin Elmer ATR- FTIR spectrometer (VersionSpectrum Two). The waste cotton fibers were pressed into a small patch so that it could be placed on the Zinc Selenide plate whereas the cellulose powders were ground with $\mathrm{KBr}$ in order to collect the spectrum. The spectra were obtained in the range of $4000 \mathrm{~cm}^{-1}-500 \mathrm{~cm}^{-1}$ with a resolution of $4 \mathrm{~cm}^{-1}$. FTIR data was used to evaluate parameters like hydrogen bond energy (HBE), hydrogen bond length $(\mathrm{HBL})$ and lateral order index (LOI) using the following equations (4), (5) and (6) respectively as described by (Poletto et al., 2014).

$$
E_{H}=\frac{1}{k} \frac{\nu_{o}-\nu}{\nu_{o}}
$$

4

Where $E_{H}$ = hydrogen bond energy for $\mathrm{OH}$ stretching bands (kJ)

$1 / \mathrm{k}=$ constant $=2.625 \times 10^{2} \mathrm{~kJ}$ 
$\nu_{O}=$ standard frequency corresponding to free $\mathrm{OH}$ groups $=3650 \mathrm{~cm}^{-1}$

$\nu=$ frequency of the bonded $\mathrm{OH}$ groups

$$
\Delta \nu\left(\mathrm{cm}^{-1}\right)=4430 \times(2.84-R)
$$

5

Where $\Delta \nu=\nu_{o}-\nu$

$\nu_{O}=$ monomeric $\mathrm{OH}$ stretching frequency $=3600 \mathrm{~cm}^{-1}$

$V=$ stretching frequency observed in IR spectrum of the sample

$\mathrm{R}=$ hydrogen bond length $(\AA)$

$\mathrm{LOI}=\mathrm{A}_{1430} / \mathrm{A}_{898}(6)$

Where $A_{1430}=$ absorbance of the band at $1430 \mathrm{~cm}^{-1}$

$A_{898}=$ absorbance of the band at $898 \mathrm{~cm}^{-1}$

\section{Result And Discussion}

\subsection{Box-Behnken Statistical Analysis}

$\mathrm{TCl}$ of WCF was found to be 0.367 before hydrolysis. TCl is the key parameter that helps in understanding the hydrogen bonding networks of cellulose. Therefore, $\mathrm{TCl}$ of the cellulose powders was chosen as the response to the input parameters that affect its hydrolysis. The experiment was conducted based on the runs provided by the BBD model and the results are tabulated as shown in Table 1. 
Table 1

Response to the experimental runs

\begin{tabular}{|c|c|c|c|c|c|c|c|c|c|}
\hline \multirow[t]{3}{*}{ Run } & \multicolumn{4}{|c|}{ Coded Variables } & \multicolumn{4}{|c|}{ Actual Variables } & \multirow{3}{*}{$\begin{array}{l}\text { Response } 1 \\
\text { TCl } \\
\%\end{array}$} \\
\hline & A & B & $\mathrm{C}$ & D & $A C(N)$ & $\mathrm{S}: \mathrm{L}(\mathrm{g}: \mathrm{ml})$ & $\mathrm{T}\left({ }^{\circ} \mathrm{C}\right)$ & $t$ (mins) & \\
\hline & & & & & & & & & \\
\hline 1 & +1 & 0 & 0 & +1 & 5 & 20 & 85 & 90 & 0.471 \\
\hline 2 & 0 & -1 & 0 & +1 & 3.75 & 15 & 85 & 90 & 0.477 \\
\hline 3 & 0 & 0 & 0 & 0 & 3.75 & 20 & 85 & 75 & 0.489 \\
\hline 4 & -1 & 0 & +1 & 0 & 2.5 & 20 & 90 & 75 & 0.488 \\
\hline 5 & 0 & +1 & -1 & 0 & 3.75 & 25 & 80 & 75 & 0.484 \\
\hline 6 & 0 & -1 & -1 & 0 & 3.75 & 15 & 80 & 75 & 0.485 \\
\hline 7 & 0 & 0 & -1 & +1 & 3.75 & 20 & 80 & 90 & 0.456 \\
\hline 8 & 0 & 0 & +1 & +1 & 3.75 & 20 & 90 & 90 & 0.501 \\
\hline 9 & 0 & 0 & -1 & -1 & 3.75 & 20 & 80 & 60 & 0.488 \\
\hline 10 & 0 & 0 & 0 & 0 & 3.75 & 20 & 85 & 75 & 0.509 \\
\hline 11 & 0 & +1 & +1 & 0 & 3.75 & 25 & 90 & 75 & 0.471 \\
\hline 12 & +1 & 0 & +1 & 0 & 5 & 20 & 90 & 75 & 0.506 \\
\hline 13 & 0 & +1 & 0 & -1 & 3.75 & 25 & 85 & 60 & 0.485 \\
\hline 14 & +1 & 0 & -1 & 0 & 5 & 20 & 80 & 75 & 0.49 \\
\hline 15 & +1 & +1 & 0 & 0 & 5 & 25 & 85 & 75 & 0.487 \\
\hline 16 & +1 & -1 & 0 & 0 & 5 & 15 & 85 & 75 & 0.486 \\
\hline 17 & -1 & 0 & -1 & 0 & 2.5 & 20 & 80 & 75 & 0.483 \\
\hline 18 & -1 & 0 & 0 & +1 & 2.5 & 20 & 85 & 90 & 0.482 \\
\hline 19 & 0 & -1 & 0 & -1 & 3.75 & 15 & 85 & 60 & 0.481 \\
\hline 20 & 0 & +1 & 0 & +1 & 3.75 & 25 & 85 & 90 & 0.488 \\
\hline 21 & -1 & +1 & 0 & 0 & 2.5 & 25 & 85 & 75 & 0.493 \\
\hline 22 & 0 & 0 & +1 & -1 & 3.75 & 20 & 90 & 60 & 0.486 \\
\hline 23 & +1 & 0 & 0 & -1 & 5 & 20 & 85 & 60 & 0.48 \\
\hline 24 & -1 & -1 & 0 & 0 & 2.5 & 15 & 85 & 75 & 0.446 \\
\hline 25 & 0 & 0 & 0 & 0 & 3.75 & 20 & 85 & 75 & 0.513 \\
\hline
\end{tabular}




\begin{tabular}{|c|c|c|c|c|c|c|c|c|c|}
\hline \multirow[t]{3}{*}{ Run } & \multicolumn{4}{|c|}{ Coded Variables } & \multicolumn{4}{|c|}{ Actual Variables } & \multirow{3}{*}{$\begin{array}{l}\text { Response } 1 \\
\text { TCl } \\
\%\end{array}$} \\
\hline & A & B & C & D & $A C(N)$ & $\mathrm{S}: \mathrm{L}(\mathrm{g}: \mathrm{ml})$ & $\mathrm{T}\left({ }^{\circ} \mathrm{C}\right)$ & t (mins) & \\
\hline & & & & & & & & & \\
\hline 26 & -1 & 0 & 0 & -1 & 2.5 & 20 & 85 & 60 & 0.389 \\
\hline 27 & 0 & -1 & +1 & 0 & 3.75 & 15 & 90 & 75 & 0.501 \\
\hline
\end{tabular}

Sequential model sum of squares (SSS) presented in Table 2 provided the data associated with the sequential sum of squares, mean squares (MS), F-value and p-value. For a statistically significant model, the F-value should be the highest and the p-value should be lowest in the SSS table. Based on the response obtained and statistical analysis between the response and the independent variables, the design suggested quadratic model as the best fit model as it has the lowest $p$-value.

Table 2

Sequential Model Sum of Squares

\begin{tabular}{|c|c|c|c|c|c|c|}
\hline Source & $\begin{array}{l}\text { Sum of } \\
\text { Squares }\end{array}$ & df & $\begin{array}{l}\text { Mean } \\
\text { Square }\end{array}$ & $\begin{array}{l}\mathrm{F} \\
\text { Value }\end{array}$ & $\begin{array}{l}\text { p-value Prob > } \\
\text { F }\end{array}$ & \\
\hline Mean vs Total & 6.28 & 1 & 6.28 & & & Suggested \\
\hline Linear vs Mean & 0.01 & 4 & 0.01 & 1.07 & 0.3957 & \\
\hline 2FI vs Linear & 0.01 & 6 & 0.01 & 1.33 & 0.3014 & \\
\hline Quadratic vs 2FI & 0.01 & 4 & 0.01 & 2.34 & 0.1150 & Suggested \\
\hline $\begin{array}{l}\text { Cubic vs } \\
\text { Quadratic }\end{array}$ & 0.01 & 8 & 0.01 & 0.95 & 0.5661 & Aliased \\
\hline Residual & 0.01 & 4 & 0.01 & & & \\
\hline Total & 6.3 & 27 & 0.24 & & & \\
\hline
\end{tabular}

In a model under consideration, the error that has occurred could be accounted on two bases: (i) lack of fit and (ii) random error. A model exhibits lack of fit when (a) it does not describe the relationship between the input factors and the response factor satisfactorily or (b) replicate data are displayed or (c) the model has omitted the important terms. For a model to be suggested, it should have insignificant lack of fit which means it should have low F-value and high P-value $>0.1$. From Table 3, it was evident that the quadratic model has insignificant lack of fit. 
Table 3

Lack of fit

\begin{tabular}{|lllllll|}
\hline Source & Sum of Squares & df & Mean Square & F Value & p-value Prob > F & \\
\hline Linear & 0.011674 & 20 & 0.000584 & 3.52 & 0.2441 & \\
\hline FI & 0.007697 & 14 & 0.00055 & 3.31 & 0.2559 & \\
\hline Quadratic & 0.004197 & 10 & 0.00042 & 2.52 & 0.3172 & Suggested \\
\hline Cubic & 0.001249 & 2 & 0.000624 & 3.73 & 0.2116 & Aliased \\
\hline Pure Error & 0.000331 & 2 & 0.000165 & & & \\
\hline
\end{tabular}

Table 4 represents the model statistics summary and the best model was chosen based on the comparison between the standard deviation (Std. Dev.) of the design error, correlation coefficient ( $R$ Squared) and Predicted Residual Error Sum of Squares (PRESS) values. For a significant model, Std. Dev. should be lower while the $R^{2}$ value should be higher. Since, a model suggested based on $R^{2}$ value alone has to be considered as biased and not completely reliable, adjusted $R^{2}$ value could be preferred. This value will provide the percentage of variation in the dependent variable after adjusting in accordance with the number of predictors added that are significant in affecting the model only. As a result, adjusted $\mathrm{R}^{2}$ helped to choose the most pertinent model. Predicted $\mathrm{R}$ squared value was used as an additional parameter that avoided over fitting a model by signifying how well a model predicted the dependent variable when the observations were removed from the model systematically. This value should be lower than R squared and closer to 1 for the model to be significant. Prediction Sum of Squares (PRESS) indicated the prediction ability of a model and it will measure the variation between fitted values and observed values. Therefore, the smaller PRESS, the better would be the predictive ability of the model. In line with this, comparing the statistical data values as provided by Table 4, it was apparent that the quadratic model holds better significance.

Table 4

Model Summary Statistics

\begin{tabular}{|lllllll|}
\hline Source & Std. Dev. & $\begin{array}{l}\text { R } \\
\text { Squared }\end{array}$ & $\begin{array}{l}\text { Adjusted R } \\
\text { Squared }\end{array}$ & $\begin{array}{l}\text { Predicted R } \\
\text { Squared }\end{array}$ & PRESS & \\
\hline Linear & 0.02336 & 0.1627 & 0.0104 & -0.2608 & 0.019 & \\
\hline 2FI & 0.0224 & 0.4410 & 0.0916 & -0.6008 & 0.024 & \\
\hline Quadratic & 0.019425 & 0.6854 & 0.3184 & -0.7308 & 0.025 & Suggested \\
\hline Cubic & 0.01987 & 0.8908 & 0.2902 & -11.4486 & 0.181 & Aliased \\
\hline
\end{tabular}

\subsubsection{Analysis of Variance}


ANOVA for the quadratic model as provided by Box-Behnken design was displayed in Table 5.The $F$ value in ANOVA table was obtained based on the ratio between regression mean square and error mean square. Therefore, the predictor terms with value not close to 1 was considered as significant. Values of Prob > F less than 0.05 indicate model terms are significant. Values greater than 0.1 indicate the model terms are not significant. Based on these conditions, $A D, A^{2}$ and $D^{2}$ are considered as significant model terms from the Table 6. In addition, the lack of fit F-value of 2.54 implies the lack of fit is not significant relative to the pure error. For a model to fit, the lack of fit should be non-significant.

Table 5

ANOVA for Response Surface Quadratic Model

\begin{tabular}{|c|c|c|c|c|c|c|}
\hline \multirow[t]{2}{*}{ Source } & \multirow[t]{2}{*}{ Sum of Squares } & \multirow[t]{2}{*}{ df } & \multirow[t]{2}{*}{ Mean Square } & \multirow[t]{2}{*}{ F Value } & \multicolumn{2}{|l|}{ p-value } \\
\hline & & & & & Prob $>F$ & \\
\hline Model & 0.009793 & 14 & 0.000699 & 1.87 & 0.1423 & \\
\hline$A-A C$ & 0.001564 & 1 & 0.001564 & 4.23 & 0.0621 & \\
\hline B-SL Ratio & $5.63 E-05$ & 1 & 5.63E-05 & 0.15 & 0.7051 & \\
\hline C-Temp & 0.000385 & 1 & 0.000385 & 1.02 & 0.3377 & \\
\hline D-Time & 0.00031 & 1 & 0.00031 & 0.83 & 0.3811 & \\
\hline$A B$ & 0.000552 & 1 & 0.000552 & 1.47 & 0.2483 & \\
\hline$A C$ & $2.5 \mathrm{E}-05$ & 1 & $2.5 \mathrm{E}-05$ & 0.081 & 0.7813 & \\
\hline$A D$ & 0.002601 & 1 & 0.002601 & 6.93 & 0.0218 & Significant \\
\hline $\mathrm{BC}$ & 0.00021 & 1 & 0.00021 & 0.56 & 0.4685 & \\
\hline BD & $3.6 \mathrm{E}-05$ & 1 & $3.6 \mathrm{E}-05$ & 0.096 & 0.7620 & \\
\hline CD & 0.000552 & 1 & 0.000552 & 1.47 & 0.2483 & \\
\hline$A^{2}$ & 0.001875 & 1 & 0.001875 & 5.04 & 0.0443 & Significant \\
\hline$B^{2}$ & 0.000331 & 1 & 0.000331 & 0.87 & 0.3687 & \\
\hline$c^{2}$ & $1.01 \mathrm{E}-05$ & 1 & $1.01 \mathrm{E}-05$ & 0.030 & 0.8648 & \\
\hline$D^{2}$ & 0.002187 & 1 & 0.002187 & 5.81 & 0.0329 & Significant \\
\hline Residual & 0.004528 & 12 & 0.000377 & & & \\
\hline Lack of Fit & 0.004197 & 10 & 0.00042 & 2.52 & 0.3172 & Not significant \\
\hline Pure Error & 0.000331 & 2 & 0.000165 & & & \\
\hline Cor Total & 0.014321 & 26 & & & & \\
\hline
\end{tabular}


The equation with coded factors and actual factors for the quadratic model as suggested by the design is given below in equations 7 and 8 respectively:

$\mathrm{TCl}=+0.50+0.011{ }^{\star} \mathrm{A}+0.00216^{\star} \mathrm{B}+0.0056{ }^{*} \mathrm{C}+0.00508^{\star} \mathrm{D}-0.012^{\star} A^{\star} \mathrm{B}$

$+0.002750 * A * C-0.025^{\star} A * D-0.00725^{\star} B{ }^{*} C+0.300 * B * D+0.012{ }^{*} C D$

$-0.019 * A^{2}-0.00787 * B^{2}-0.001458 * C^{2}-0.020 * D^{2}(7)$

$\mathrm{TCl}=-0.69883+0.20180 * \mathrm{AC}+0.041733^{*} \mathrm{SL}$ Ratio $+0.00343 * \mathrm{~T}+0.00479 * \mathrm{Time}$

$-0.00188 * A C * S L$ Ratio $+0.004 * A C * T-0.00136 * A C * T$ Time $-0.0029 *$

SL Ratio*T + 4.000E-5*SL Ratio*Time + 1.567E-4*T*Time-0.012000

${ }^{\star} \mathrm{AC}{ }^{2}-3.15 \mathrm{E}-4 * \mathrm{SL}$ Ratio ${ }^{2}-5.800 \mathrm{E}-5 * \mathrm{~T}^{2}-9.000 \mathrm{E}-5 * \mathrm{Time}^{2}$ (8)

The final equation in terms of coded factors helps in plotting the diagnostic graphs and optimizing the data. The final equation in terms of actual factors helps in predicting the response based on the actual factors. According to Eq. 8, the TCl response which was predicted by the design for the design points, the actual response and the residual term are shown in Table 6 . The residual term is obtained as a difference between actual and predicted value. 
Table 6

Diagnostics of experimental runs

\begin{tabular}{|c|c|c|c|}
\hline Run & Actual Value & Predicted Value & Residual \\
\hline 1 & 0.446 & 0.452 & -0.006 \\
\hline 2 & 0.486 & 0.499 & -0.013 \\
\hline 3 & 0.493 & 0.48 & 0.014 \\
\hline 4 & 0.486 & 0.479 & 0.008 \\
\hline 5 & 0.488 & 0.484 & 0.005 \\
\hline 6 & 0.486 & 0.471 & 0.016 \\
\hline 7 & 0.456 & 0.47 & -0.014 \\
\hline 8 & 0.501 & 0.505 & -0.004 \\
\hline 9 & 0.389 & 0.423 & -0.034 \\
\hline 10 & 0.48 & 0.497 & -0.017 \\
\hline 11 & 0.482 & 0.484 & -0.002 \\
\hline 12 & 0.471 & 0.456 & 0.016 \\
\hline 13 & 0.485 & 0.48 & 0.006 \\
\hline 14 & 0.484 & 0.499 & -0.015 \\
\hline 15 & 0.501 & 0.506 & -0.005 \\
\hline 16 & 0.471 & 0.495 & -0.024 \\
\hline 17 & 0.483 & 0.47 & 0.014 \\
\hline 18 & 0.49 & 0.487 & 0.004 \\
\hline 19 & 0.488 & 0.475 & 0.014 \\
\hline 20 & 0.506 & 0.504 & 0.003 \\
\hline 21 & 0.486 & 0.472 & 0.015 \\
\hline 22 & 0.485 & 0.47 & 0.016 \\
\hline 23 & 0.477 & 0.476 & 0.002 \\
\hline 24 & 0.488 & 0.486 & 0.003 \\
\hline 25 & 0.509 & 0.504 & 0.006 \\
\hline 26 & 0.513 & 0.504 & 0.01 \\
\hline 27 & 0.489 & 0.504 & -0.015 \\
\hline
\end{tabular}


Figure 1.a portrayed actual response values against predicted values. The relationship between actual and predicted values is linear for best fit model. But due to deviation of actual value from predicted value, residuals are found as seen in the Fig. 1.a. Only few actual values fall in line with predicted value and hence convey less adequacy of the model fitting the data. Nevertheless, most of the values lie closer to the prediction line and therefore the quadratic model could be considered best for the data optimization of the input parameters that affect the $\mathrm{TCl}$ response of the cellulose powders.

\subsubsection{Diagnostic Plots of the Model}

Figure 1. b. depicted the normal plot of residuals which helps in understanding the normal distribution of the residual terms. When the plot of residuals follows approximately a linear pattern, then according to the design, the residuals are said to be normally distributed. Figure 1.c. showed the plot of predicted vs studentized residuals. For a linear regression model, the data points in this plot should be randomly scattered as observed in Fig. 1.c. A plot of the experimental run order versus residuals is shown in Fig. 1.d.. This plot helps in analyzing the influence of the lurking variables during the experiment on the response variable. The lurking variable hides the true relationship between the independent variables and their effect on the response by interpreting a false relationship among them. For a response to be free from the influence of the lurking variables, the residuals vs run plot should follow a random scattered pattern. Therefore, it was understood from the Fig. 1.d., no such lurking variable was present in the experiment and that the true relationship between the independent variables was maintained.

Statistically, the model terms that have $p$-value less than 0.05 are significant. Therefore, based on the ANOVA results from Table 6 , it was evident that $A D, A^{2}$ and $D^{2}$ have significant effect on the $T C l$ of cellulose powders. Since a contour and 3D graph helps in understanding the interaction of the predictor factors on the response factor better, the effect of the significant model term $A D$ (where A-acid concentration and D-time) was illustrated in Fig. 2a. and b. respectively. It was understood from the figure that when the concentration of the acid and the time are in the central points, a maximum TCl was obtained. On the other hand, low acid concentration and low reaction time, lowers $\mathrm{TCl}$ of the cellulose powders.

\subsection{Optimization of Process Parameters}

Optimization of $\mathrm{TCl}$ was done by choosing process parameters within the selected range of low and high level and maximizing the response parameter. The software furnished 25 optimum solutions with desirability value 1 . One solution with parameter combination of $A C-4.33 \mathrm{~N}, \mathrm{~S} / \mathrm{L}$ ratio- $1: 16.76 \mathrm{~g} / \mathrm{ml}, \mathrm{T}-$ $90^{\circ} \mathrm{C}$ and t-76.24 minutes that provided the maximum $\mathrm{TCl}$ of 0.518 was opted for the desirability test. Three trials were performed using above condition and the average $\mathrm{TCl}$ has been compared with suggested solution in Table 7. Consequently, a combination of $A C-4.3 \mathrm{~N}, \mathrm{~S} / \mathrm{L}$ ratio- $1: 16.7 \mathrm{~g} / \mathrm{ml}, \mathrm{T}-90^{\circ} \mathrm{C}$ and t-76 minutes was considered to be optimum for obtaining maximum TCl cellulose powders from waste cotton fibers. 
Table 7

Comparison of desirability test with experimental data

\begin{tabular}{|lll|}
\hline Process Parameters & Desired Solution & Experimental Data \\
\hline Acid Concentration $(\mathrm{N})$ & 4.33 & 4.3 \\
\hline Solid/Liquid Ratio $(\mathrm{g} / \mathrm{ml})$ & $1: 16.76$ & $1: 16.7$ \\
\hline Temperature $\left({ }^{\circ} \mathrm{C}\right)$ & 90 & 90 \\
\hline Time $($ minutes $)$ & 76.24 & 76 \\
\hline TCl & 0.518 & 0.515 \\
\hline
\end{tabular}

\subsection{FESEM Analysis}

The micrographs of WCF and MTCl acquired from FE-SEM are depicted in Fig. 3.a and b respectively. Apparently, the continuous filament network of WCF was ruptured down after hydrolysis and appeared to be rod-like particles of irregular size and shape. The inset in Fig. 3(b) showed the asymmetrical cleavage of a cotton fiber which lead to the irregular size and shape of $\mathrm{MTCl}$ particles. The average diameter of WCF was found to be 19.22 microns while the average diameter of $\mathrm{MTCl}$ was reduced to 8.84 microns after hydrolysis. The average length of WCF was measured to be $4.5 \mathrm{~cm}$ and that of MTCl was reduced to 24.6 microns. This reduction in particle size of MTCl sample has caused the particles to coalesce as seen from the micrograph of $\mathrm{MTCl}$ due to increase in the number of contact points per $\mathrm{MTCl}$ particle (Metzger et al., 2020).

\subsection{Colour Identification Test}

The cellulose samples obtained from cotton fiber was almost white in colour, odorless, tasteless with free flowing powdery texture. In order to confirm microcrystalline nature qualitatively as observed from FESEM results, the MTCI sample was subjected to colour identification test. lodinated zinc chloride solution was prepared as described by (Ejikeme, 2008). The test involved treating $0.01 \mathrm{~g}$ of MTCl powder with $2 \mathrm{ml}$ iodinated Zinc Chloride solution. A change in colour from white to violet-blue was inferred which confirmed that the MTCl particles were microcrystalline.

\subsection{XPS Analysis}

XPS analysis was performed in the current study to ascertain the significant removal of contaminants and effect of hydrolysis on cellulose polymer. A comparison of wide scan spectrum of WCF and MTCI is portrayed in Fig. 5.a and the presence of carbon and oxygen in the surface of both samples was clearly discernible. The atomic percentage of $\mathrm{C}$ and $\mathrm{O}$ as derived from wide scan spectra and that of carbon components from high resolution spectra for WCF and $\mathrm{MTCl}$ are provided in the Table 8 . The $\mathrm{O} / \mathrm{C}$ ratio has increased from 0.47 to 0.57 in $\mathrm{MTCl}$ particles which could be attributed to the removal of noncellulosic components considerably. 
The high resolution spectra of $\mathrm{C} 1$ s peak of WCF and $\mathrm{MTCl}$ after deconvolution are displayed in the Fig. 5 (b) and (c) respectively. The deconvoluted peaks are represented as C I, C II and C III starting from the lower binding energy. As seen from the Figs. 5.b and c, the intensity of $\mathrm{CI}$ deconvoluted peak has decreased by $7.4 \%$ in $\mathrm{MTCl}$ spectrum which could be due to the removal of contaminants or impurities. The same was reflected in the improved $\mathrm{O} / \mathrm{C}$ ratio from the survey spectra of $\mathrm{MTCl}$ sample. The intensity of C II peak increased while that of C III peak decreased in the deconvoluted spectrum of $\mathrm{MTCl}$ when compared to WCF. The reason could be attributed to the rupture of hydrogen bonds and glycosidic bonds that exist between the cellulose molecules (Pan et al., 2013).

Table 8

XPS Wide Scan and High Resolution Scan Elemental Composition of WCF and MTCI

\begin{tabular}{|lllllll|}
\hline Sample & \multicolumn{3}{l}{ Wide Scan Atomic Concentration } & \multicolumn{3}{l|}{ High Resolution C1s Carbon Composition (\%) } \\
\cline { 2 - 7 } & $\mathbf{C ~ ( \% ) ~}$ & $\mathbf{O}(\%)$ & O/C Ratio & C I & C II & C III \\
\hline WCF & 67.7 & 31.8 & 0.47 & 46.7 & 34.4 & 19.0 \\
\hline MTCl & 63.8 & 36.21 & 0.57 & 39.3 & 40.8 & 13.3 \\
\hline
\end{tabular}

\subsection{XRD Analysis}

The structure of the cellulose chain, its arrangement and the bonding between these chains are the prime factors that contribute to the crystallinity of the cellulose polymer. These factors could be inferred from Xray diffraction studies by determining the unit cell parameters, crystallite size and crystallinity index of the material under consideration. X-Ray patterns of WCF and $\mathrm{MTCl}$ are illustrated in Fig. 6 . In the current study, the cellulose I $\beta$ model as suggested by (Nishiyama et al., 2002) was followed wherein the c-axis direction was considered the fiber axis, the intramolecular $\mathrm{H}$-bonds orient along a-axis and the intermolecular $\mathrm{H}$-bonds orient along b-axis direction of the unit cell. Presence of peaks at $22.7^{\circ}, 14.8^{\circ}$ and $16.5^{\circ} 2 \theta$ from the reflections of $(200),(1-10)$ and $(110)$ respectively confirmed cellulose I $\beta$ crystal structure before and after hydrolysis. In line with the discussions of (French, 2014), it has been understood that these reflections are the main peak contributors in the XRD pattern of cellulose I $\beta$. The low intense peak at $34.5^{\circ}$ is a composite of other neighboring reflections and hence is not a dominant contributor. During $x$-ray analysis, WCF was pressed onto the sample holder such that the fiber axis and the plane of surface of sample holder lies parallel to each other giving rise to preferred orientation. Whereas, the $\mathrm{MTCl}$ particles were sprinkled onto the sample holder and hence a shoulder peak appears at $20.6^{\circ}$ corresponding to (102) plane is divulged indicating the random orientation pattern. Both preferred and random orientation of crystallites of the WCF and MTCI are visible in Fig. 6.

Lattice constants of WCF and MTCI as calculated from the inherent reflections of cellulose I $\beta$ viz., (1-10), (110), (200) and (004), the crystallite size and Segal $\mathrm{Cl}$ are listed in Table 9. It was evident that the intramolecular $\mathrm{H}$-bonds contracts while the intermolecular $\mathrm{H}$-bonds stretches as perceptible from the decrease in the a-dimension and increase in the b-dimension of the MTCl crystallites. after hydrolysis. 
The contraction of intra $\mathrm{H}$-bonds and stretching of inter $\mathrm{H}$-bonds might counterbalance any change in the C1-0-C4 glycosidic bond length. This notion was justifiable due to the absence of change in the cparameter of the $\mathrm{MTCl}$ crystal. Further, the reason for decrease, increase and null change in $\mathrm{a}, \mathrm{b}$ and $\mathrm{c}$ lattice parameter values respectively is discussed at length using FTIR spectral analysis. Secondly, the crystallite size of $\mathrm{MTCl}$ has increased from $4.7 \mathrm{~nm}$ to $5.4 \mathrm{~nm}$. Dissolution of amorphous segment during hydrolysis would have allowed the cellulose molecules in the crystalline portion to relax and rearrange the cellulose chains in lateral direction such that the average crystallite size increases in $\mathrm{MTCl}$. Next, the $\mathrm{Cl}$ of $\mathrm{MTCl}$ has improvised by $8 \%$ which affirmed the increase in crystalline segments by removing the amorphous segments due to hydrolysis. All these outcomes from XRD analysis will be correlated with FTIR discussions in the following section.

Table 9

Lattice parameters, crystallinity index and crystallite size of WCF and MTCl

\begin{tabular}{|lll|}
\hline Sample Parameters & WCF & MTCI \\
\hline $\mathrm{a}(\AA)$ & 7.91 & 7.86 \\
$\mathrm{~b}(\AA)$ & 8.27 & 8.37 \\
$\mathrm{c}(\AA)$ & 10.39 & 10.39 \\
\hline $\mathrm{Y}\left({ }^{\circ}\right)$ & 95.6 & 96.8 \\
\hline Crystallite Size $(\mathrm{nm})$ & 4.7 & 5.4 \\
\hline Crystallinity Index $(\%)$ & 86.4 & 93.7 \\
\hline
\end{tabular}

\subsection{ATR-FTIR analysis}

It is believed that almost all $\mathrm{OH}$ bonds in a cellulose crystal are engaged in highly coupled and delocalized intra and inter chain hydrogen bonds (Lee et al., 2015). During acid hydrolysis of cotton fibers, the amorphous segments gets solvated leaving behind the crystalline segment intact depending on the reaction conditions. This process results in change in the nature of hydrogen bond linkages which could be understood by subjecting the samples to FTIR analysis before and after acid hydrolysis. Since the hydrogen's ability to scatter X-rays are weak, both XPS and XRD were not capable of elucidating the role of hydrogen bond network completely. Yet, FTIR spectroscopic technique bestowed individual hydrogen bonding frequencies upon deconvolution of the spectrum with better precision. Peak positions and assignments to the peaks derived from the spectra of WCF and MTCl were displayed in Table 10. The spectra was divided into three segments viz., $3500-3000 \mathrm{~cm}^{-1}, 3000-2800 \mathrm{~cm}^{-1}$ and $1700-600 \mathrm{~cm}^{-1}$ for the purpose of analysis.

4.7.1 Region $3500-3000 \mathrm{~cm}^{-1}$ This region comprises of interactions of all types of intra- and inter molecular hydrogen bonds of cellulose which are imbricated on each other such that a band is formed encompassing the region $3500-3000 \mathrm{~cm}^{-1}$. Hence, deconvolution of the spectra in this region was 
performed and analyzed in Fig. 7. Profound differences were observed in the region such as relative peak broadening, peak symmetry and increase in peak intensity which offered interesting facets pertaining to the hydrogen bonding system of cellulose after acid hydrolysis. The resolved spectrum of WCF showed peaks at $3482,3395,3340,3275$ and $3132 \mathrm{~cm}^{-1}$. As observed from the spectrum, the inter-chain vibration $60 \mathrm{H} \cdots 30\left(3275 \mathrm{~cm}^{-1}\right)$ contributed the most to the peak whereas the coupled hydrogen bond interactions $20 \mathrm{H} \cdots 6 \mathrm{OH} \cdots 3 \mathrm{OH} \cdots 50\left(3340 \mathrm{~cm}^{-1}\right)$ contributed the least. This led to conclusion that the intermolecular $\mathrm{H}$-bonds plays the dominant role in holding the cellulose chains to bundle up into microfibrils. Taking into account that these peaks arise due to the combined contributions from crystalline and amorphous segments, the peaks 3395, 3340 and $3132 \mathrm{~cm}^{-1}$ which are present in WCF vanished in $\mathrm{MTCl}$. This showed that the $3 \mathrm{OH} \cdots 50$ intra-chain $\left(3395 \mathrm{~cm}^{-1}\right)$ and the coupled hydrogen bond networks $\left(3340 \mathrm{~cm}^{-1}\right)$ of the cellulose chains are more prone to protonic strike of the acids. In addition, the peak $3132 \mathrm{~cm}^{-1}$ which correspond to the stretching vibration of 2,3 and $6 \mathrm{OH}$ groups that are actively engaged in bonding are also more prone to acidic attack as inferred by the disappearance of this peak. These peaks could perhaps be the interfacial bonds between crystalline and amorphous segments and the solvation of most part of amorphous segments could have affected these bonds. This would result in dangling or free $\mathrm{OH}$ bonds in the cellulose molecule of the crystalline portion which was in line with the increase in intensity of C II sub-peak as seen from XPS analysis. Figure 8 demonstrates the structure of cellulose molecule before and after hydrolysis.

In spite of cleavage of all said bonds, the crystalline nature of cellulose was preserved in $\mathrm{MTCl}$ due to the immense contribution of $20 \mathrm{H} \cdots 60$ intra-chain $\left(3482 \mathrm{~cm}^{-1}\right)$ and $60 \mathrm{H} \cdots 03$ inter-chain $\left(3275 \mathrm{~cm}^{-1}\right)$ hydrogen bonds as seen from Fig. 9b. A red shift from $3482 \mathrm{~cm}^{-1}$ to $3471 \mathrm{~cm}^{-1}$ in MTCl indicated the shortening of $20 \mathrm{H} \cdots 60$ hydrogen bond length which in turn increased the $20 \mathrm{H} \cdots 60$ intra-molecular $\mathrm{H}$ bond energy (Altaner et al., 2014). Conversely, the peak $3275 \mathrm{~cm}^{-1}$ was blue shifted to $3287 \mathrm{~cm}^{-1}$ in MTCl which denoted the lengthening of $60 \mathrm{H} \cdots 03 \mathrm{H}$-bond. The shortening and lengthening of intra- and inter-molecular $\mathrm{H}$-bond lengths was in accord with the XRD results that interpreted a decrease in adimension and increase in b-dimension respectively in the $\mathrm{MTCl}$ crystal. Consequently, the intra-molecular $\mathrm{H}$-bond energy strengthens while the inter-molecular $\mathrm{H}$-bond energy weakens post hydrolysis of WCF. The stretching of $60 \mathrm{H} \cdots 03 \mathrm{H}$-bond reduced the inter-molecular $\mathrm{H}$-bond energy thereby increasing the $6 \mathrm{O}-\mathrm{H}$ bond energy. On the whole, the modification in bond energy was poised in such a manner that when the hydrogen bond energy decreases, the covalent bond energy of that particular donor hydroxyl molecule increases, thus upholding the overall energy of the cellulose structure. HBE, HBL and LOI were calculated using the equations (1), (2) and (3) respectively and are enlisted in Table 11. HBE and HBL values obtained was in accordance with the above explanation. An increase in LOI indicated transformation of cellulose fibers towards higher crystallinity in $\mathrm{MTCl}$ which was corroborated by XRD. Figure (8) portrayed the nature of hydrogen bonds in WCF and MTCI before and after hydrolysis. 
Peak Characteristics of Cellulose before and after hydrolysis

\begin{tabular}{|c|c|c|c|}
\hline \multicolumn{2}{|c|}{ Peak Position } & \multirow[t]{2}{*}{ Peak Assignment } & \multirow[t]{2}{*}{ Reference } \\
\hline WCF & MTCl & & \\
\hline 3482 & 3471 & $\begin{array}{l}20-\mathrm{H} \cdots \mathrm{O} 66 \text { intra-molecular hydrogen bond stretching } \\
\text { vibration }\end{array}$ & $\begin{array}{l}\text { (Ivanova et al., } \\
\text { 1989) }\end{array}$ \\
\hline 3395 & - & $\begin{array}{l}30-\mathrm{H} \cdots 50 \text { intra-molecular hydrogen bond stretching } \\
\text { vibration }\end{array}$ & $\begin{array}{l}\text { (Ivanova et al., } \\
\text { 1989) }\end{array}$ \\
\hline 3340 & - & $\begin{array}{l}\text { Coupled hydrogen bond stretching vibration } 20-\mathrm{H} \cdots 60- \\
\mathrm{H} \cdots 30-\mathrm{H} \cdots 50\end{array}$ & (Lee et al., 2015) \\
\hline 3275 & 3287 & $\begin{array}{l}60-\mathrm{H} \cdots 30 \text { inter-molecular hydrogen bond stretching } \\
\text { vibration }\end{array}$ & $\begin{array}{l}\text { (Ivanova et al., } \\
\text { 1989) }\end{array}$ \\
\hline 3132 & - & $\begin{array}{l}\text { Valence vibration of bonded } \mathrm{OH} \text { groups corresponding to } 20 \\
-\mathrm{H}, 3 \mathrm{O}-\mathrm{H} \& 6 \mathrm{O}-\mathrm{H}\end{array}$ & $\begin{array}{l}\text { (Schwanninger et } \\
\text { al., 2004) }\end{array}$ \\
\hline 2965 & 2969 & $\mathrm{CH}_{2}$ asymmetric stretching & \multirow[t]{4}{*}{ (Lee et al., 2015) } \\
\hline 2932 & 2947 & $\mathrm{CH}_{2}$ asymmetric stretching & \\
\hline 2898 & 2906 & Ring $\mathrm{CH}$ stretching & \\
\hline 2857 & 2852 & $\mathrm{CH}_{2}$ symmetric stretching & \\
\hline 1747 & 1737 & $\begin{array}{l}\mathrm{C}=\mathrm{O} \text { stretch in unconjugated ketones, carbonyls and in ester } \\
\text { groups }\end{array}$ & \multirow[t]{5}{*}{$\begin{array}{l}\text { (Schwanninger et } \\
\text { al., 2004) }\end{array}$} \\
\hline 1655 & - & $C=0$ stretch in conjugated $p$-substituted aryl ketones & \\
\hline 1634 & 1650 & Adsorbed water & \\
\hline 1589 & - & \multirow[t]{2}{*}{ Aromatic skeletal vibrations and $\mathrm{C}=\mathrm{O}$ stretch } & \\
\hline 1530 & - & & \\
\hline 1427 & 1428 & $\mathrm{CH}_{2}$ scissoring & \multirow{5}{*}{$\begin{array}{l}\text { (Nelson \& O'Connor, } \\
\text { 1964) }\end{array}$} \\
\hline 1370 & 1370 & $\mathrm{C}-\mathrm{H}$ bending & \\
\hline 1334 & - & $\mathrm{O}-\mathrm{H}$ in plane bending & \\
\hline 1314 & 1317 & $\mathrm{CH}_{2}$ wagging & \\
\hline 1280 & 1281 & $\mathrm{C}-\mathrm{H}$ bending & \\
\hline 1161 & 1161 & $\mathrm{C}-\mathrm{O}-\mathrm{C}$ asymmetric valence vibration & \multirow{3}{*}{$\begin{array}{l}\text { (Schwanninger et } \\
\text { al., 2004) }\end{array}$} \\
\hline 1107 & 1118 & Ring asymmetric valence vibration & \\
\hline 1054 & 1042 & $\mathrm{C}-\mathrm{O}$ valence vibration mainly from $\mathrm{C} 3-\mathrm{O} 3 \mathrm{H}$ & \\
\hline
\end{tabular}




\begin{tabular}{|c|c|c|c|}
\hline \multicolumn{2}{|c|}{ Peak Position } & \multirow[t]{2}{*}{ Peak Assignment } & \multirow[t]{2}{*}{ Reference } \\
\hline WCF & $\mathrm{MTCl}$ & & \\
\hline 1030 & - & Aromatic $\mathrm{C}-\mathrm{H}$ in plane deformation & \\
\hline 1000 & - & $\mathrm{C}-\mathrm{O}$ deformation in primary alcohols & \\
\hline 984 & - & $\mathrm{C}-\mathrm{O}$ valence vibration & \\
\hline 896 & 898 & Anomere $\mathrm{C}$-groups, $\mathrm{C} 1-\mathrm{H}$ deformation, ring valence vibration & \\
\hline 706 & 709 & Rocking vibration of $\mathrm{CH}_{2}$ in cellulose $\mathrm{I} \beta$ & \\
\hline 664 & 671 & $\mathrm{C}-\mathrm{OH}$ out-of-plane bending mode & \\
\hline
\end{tabular}

Table 11

$\mathrm{HBI}, \mathrm{HBE}$ and $\mathrm{LOI}$ values of WCF and $\mathrm{MTCl}$

\begin{tabular}{|c|c|c|c|c|c|}
\hline \multirow[t]{5}{*}{ Sample } & \multicolumn{2}{|l|}{ HBE (kJ) } & \multicolumn{2}{|l|}{ HBL $(\AA ̊)$} & \multirow{5}{*}{$\begin{array}{l}\text { LOI } \\
\text { (A1430/A898) }\end{array}$} \\
\hline & $\begin{array}{l}\text { Intra- } \\
\text { molecular }\end{array}$ & $\begin{array}{l}\text { Inter- } \\
\text { molecular }\end{array}$ & $\begin{array}{l}\text { Intra- } \\
\text { molecular }\end{array}$ & $\begin{array}{l}\text { Inter- } \\
\text { molecular }\end{array}$ & \\
\hline & $(2 \mathrm{OH} \cdots$ & $(60 \mathrm{H} \cdots$ & $(20 \mathrm{H} \cdots$ & $(6 \mathrm{OH} \cdots$ & \\
\hline & $60)$ & 30) & 60) & 30) & \\
\hline & $(3480-3450)$ & $(3290-3270)$ & $(3480-3450)$ & $(3290-3270)$ & \\
\hline WCF & 13.74 & 26.97 & 2.8134 & 2.7667 & 0.1 \\
\hline HTCP & 12.37 & 26.11 & 2.8109 & 2.7694 & 3.0 \\
\hline
\end{tabular}

\subsubsection{Region $3000-2800 \mathrm{~cm}^{-1}$}

This region correspond to the symmetric and antisymmetric stretching vibrations of methine groups at $\mathrm{C} 1$ to $\mathrm{C} 5$ positions and methylene group at $\mathrm{C} 6$ position of cellulose unit cell. The $\mathrm{C}^{-} \mathrm{H}_{2}$ asymmetric stretching peaks 2965, 2932 and $2898 \mathrm{~cm}^{-1}$ in WCF are shifted to higher frequencies in $\mathrm{MTCl}$ while the $\mathrm{C}^{6} \mathrm{H}_{2}$ symmetric stretching peak $2857 \mathrm{~cm}^{-1}$ was shifted to low frequency as seen from the Table 10 and Fig. 9. The increased frequency of $\mathrm{CH}_{2}$ asymmetric stretching denoted the strengthening of $\mathrm{C}-\mathrm{H}$ as a result of weakening of inter-sheet hydrogen bond due to acid hydrolysis. Hence it was concluded that the acid hydrolysis affected the intersheet hydrogen bonding the most. Contrarily, the red shift of $\mathrm{CH}_{2}$ symmetric stretching frequency indicated the weakening of $\mathrm{H}-\mathrm{C} 6-\mathrm{H}$ bond which would consecutively enhance the intra-molecular $\mathrm{H}$-bond energy as perceived earlier.

\subsubsection{Region $1800-650 \mathrm{~cm}^{-1}$}

The peak $1634 \mathrm{~cm}^{-1}$ attributed to the $\mathrm{O}-\mathrm{H}$ bending of adsorbed water was accentuated in the MTCI spectrum. Increase in surface area and availability of free hydroxyl groups would tend to increase the 
affinity for moisture in $\mathrm{MTCl}$ and hence an accentuation of $1634 \mathrm{~cm}^{-1}$ peak was spotted. Spectra of $\mathrm{MTCl}$ in the fingerprint region showed appreciable disparity in the intensity of almost all peaks and blue shift in certain peaks when compared to WCF. The peak at $1427 \mathrm{~cm}^{-1}$ was blue shifted to $1429 \mathrm{~cm}^{-1}$ and showed an increased intensity which confirmed the presence of more crystalline cellulose I content in $\mathrm{MTCl}$ ((Kljun et al). The bands at 1370 and $1314 \mathrm{~cm}^{-1}$ was ascribed to the bending vibrations of $\mathrm{CH}$ and $\mathrm{CH}_{2}$ groups. No shift was observed in 1370 which affirmed the intactness of cellulose ring after hydrolysis. On the other hand, a blue shift was observed in $1314 \mathrm{~cm}^{-1}$ peak which correspond to any alterations in the $\mathrm{C} \mathrm{H}_{2}$ background as discussed earlier. The peaks that were conspicuous in WCF spectra viz 1161, 1107, 1054 and $1030 \mathrm{~cm}^{-1}$ disappeared and emerged as a strong band sprawling between 1190 and $930 \mathrm{~cm}^{-1}$ in $\mathrm{MTCl}$. This appeared as though the amorphous section was impaired during the hydrolysis giving a broad band with centre point at $1107 \mathrm{~cm}^{-1}$. The $1107 \mathrm{~cm}^{-1}$ peak correspond to asymmetric ring stretch vibration. The peak $1161 \mathrm{~cm}^{-1}$ corresponding to $\mathrm{C}-\mathrm{O}-\mathrm{C}$ stretching appeared as a shoulder peak to $1107 \mathrm{~cm}^{-1}$. Neither peak showed any shift after hydrolysis which corroborated XRD result of the absence of change in c-parameter. There was a mild blue shift and evident increase in the intensity of the $896 \mathrm{~cm}^{-1}$ peak which could be attributed to the changes around $\mathrm{C} 1$ and the surrounding valence atoms. This denoted that these bonds were strengthened after hydrolysis. From the above discussions, it could be concluded that $\mathrm{MTCl}$ had improved intra- and inter- molecular $\mathrm{H}$-bonds which could reason out for the high $\mathrm{TCl}$ of the sample as indicated by BBD. Also, it was justified that at places where $\mathrm{H}$-bond weakened, the associated covalent bond strengthened and vice-versa.

\section{Conclusions}

In the present study, Box Behnken design was used to optimize the process parameters of the acid hydrolysis of waste cotton fiber to obtain maximum $\mathrm{TCl}$ in the given parameter range. The design proposed quadratic model as the best model and the optimum condition to obtain MCC with maximum $\mathrm{TCl}$ from waste cotton fiber is acid concentration- $4.3 \mathrm{~N} \mathrm{HCl}$, solid: liquid ratio- $1 \mathrm{~g}: 16.7 \mathrm{ml}$, temperature$90^{\circ} \mathrm{C}$ and time-76 mins. FESEM studies aided to scrutinize the rupture of cotton fibers while the colour identification test helped to confirm qualitatively that the cellulose particles obtained after hydrolysis were microcrystalline in nature. XPS studies helped to understand the purity and effect of hydrolysis at the surface level of MTCl. XRD analysis confirmed the crystalline make-up of cellulose was not affected in the given conditions of acid hydrolysis process whereas ATR-FTIR analysis revealed breakage of interchain hydrogen bonds and rearrangement of intra-chain hydrogen bonds to form microcrystals. On the whole, the involvement of $\mathrm{H}$-bond and covalent bond was improved after the acid hydrolysis reaction proposed by the BBD and the synergism between these bonds helped to attain maximum $\mathrm{TCl}$ in $\mathrm{MCC}$ particles.

\section{Declarations}

The authors would like to thank the Management of PSG College of Technology for providing the necessary infrastructure to carry out the work. 


\section{Funding}

This work was financially supported by the Department of science of Technology (DST), New Delhi, India, under the Woman Scientist Scheme - A (WoS-A).File No- SR/WOS-A/ET-90/2017.

\section{Conflict of interest}

Not Applicable

\section{Author Contributions}

Vishnu Prabha Muthusamy: Prepared the samples, characterized, compiled and analyzed the data, and wrote the manuscript.

Vaideki Krishnakumar: Conceptualization, Supervision, and Validation.

\section{References}

1. Altaner, C. M., Thomas, L. H., Fernandes, A. N., \& Jarvis, M. C. (2014). How cellulose stretches: Synergism between covalent and hydrogen bonding. Biomacromolecules, 15(3), 791-798. https://doi.org/10.1021/bm401616n

2. Chaturvedi, V., \& Verma, P. (2013). An overview of key pretreatment processes employed for bioconversion of lignocellulosic biomass into biofuels and value added products. 3 Biotech, 3(5), 415-431. https://doi.org/10.1007/s13205-013-0167-8

3. Ejikeme, P. M. (2008). Investigation of the physicochemical properties of microcrystalline cellulose from agricultural wastes I: Orange mesocarp. Cellulose, 15(1), 141-147. https://doi.org/10.1007/s10570-007-9147-7

4. Farahbakhsh, N., Venditti, R. A., \& Jur, J. S. (2014). Mechanical and thermal investigation of thermoplastic nanocomposite films fabricated using micro- and nano-sized fillers from recycled cotton T-shirts. Cellulose, 21(4), 2743-2755. https://doi.org/10.1007/s10570-014-0285-4

5. Fras, L., Johansson, L. S., Stenius, P., Laine, J., Stana-Kleinschek, K., \& Ribitsch, V. (2005). Analysis of the oxidation of cellulose fibres by titration and XPS. Colloids and Surfaces A: Physicochemical and Engineering Aspects, 260(1-3), 101-108. https://doi.org/10.1016/j.colsurfa.2005.01.035

6. French, A. D. (2014). Idealized powder diffraction patterns for cellulose polymorphs. Cellulose, 21(2), 885-896. https://doi.org/10.1007/s10570-013-0030-4

7. Ilyas, R. A., Sapuan, S. M., \& Ishak, M. R. (2018). Isolation and characterization of nanocrystalline cellulose from sugar palm fibres (Arenga Pinnata). Carbohydrate Polymers, 181, 1038-1051. https://doi.org/10.1016/j.carbpol.2017.11.045

8. Ivanova, N. V., Korolenko, E. A., Korolik E., V., Zhbankov R. G. IR Spectrum of Cellulose. Cellulose, 51(2), 847-851. https://doi.org/ 10.1007\%2FBF00659967 
9. Kljun, A., Benians, T. A. S., Goubet, F., Meulewaeter, F., Knox, J. P., \& Blackburn, R. S. (2011). Comparative analysis of crystallinity changes in cellulose i polymers using ATR-FTIR, X-ray diffraction, and carbohydrate-binding module probes. Biomacromolecules, 12(11), 4121-4126. https://doi.org/10.1021/bm201176m

10. Lee, C. M., Kubicki, J. D., Fan, B., Zhong, L., Jarvis, M. C., \& Kim, S. H. (2015). Hydrogen-Bonding Network and $\mathrm{OH}$ Stretch Vibration of Cellulose: Comparison of Computational Modeling with Polarized IR and SFG Spectra. Journal of Physical Chemistry B, 119(49), 15138-15149. https://doi.org/10.1021/acs.jpcb.5b08015

11. Ling, Z., Edwards, J. V., Guo, Z., Prevost, N. T., Nam, S., Wu, Q., French, A. D., \& Xu, F. (2019). Structural variations of cotton cellulose nanocrystals from deep eutectic solvent treatment: micro and nano scale. Cellulose, 26(2), 861-876. https://doi.org/10.1007/s10570-018-2092-9

12. Ly, B., Thielemans, W., Dufresne, A., Chaussy, D., \& Belgacem, M. N. (2008). Surface functionalization of cellulose fibres and their incorporation in renewable polymeric matrices. Composites Science and Technology, 68(15-16), 3193-3201. https://doi.org/10.1016/j.compscitech.2008.07.018

13. Metzger, C., Auber, D., Dähnhardt-Pfeiffer, S., \& Briesen, H. (2020). Agglomeration of cellulose nanocrystals: the effect of secondary sulfates and their use in product separation. Cellulose, 27(17), 9839-9851. https://doi.org/10.1007/s10570-020-03476-0

14. Nam, S., French, A. D., Condon, B. D., \& Concha, M. (2016). Segal crystallinity index revisited by the simulation of X-ray diffraction patterns of cotton cellulose I $\beta$ and cellulose II. Carbohydrate Polymers, 135(January 2016), 1-9. https://doi.org/10.1016/j.carbpol.2015.08.035

15. Nelson, M. L., \& O’Connor, R. T. (1964). Relation of certain infrared bands to cellulose crystallinity and crystal lattice type. Part II. A new infrared ratio for estimation of crystallinity in celluloses I and II. Journal of Applied Polymer Science, 8(3), 1325-1341. https://doi.org/10.1002/app.1964.070080323

16. Nishiyama, Y., Langan, P., \& Chanzy, H. (2002). Crystal structure and hydrogen-bonding system in cellulose $\mathrm{I} \beta$ from synchrotron $X$-ray and neutron fiber diffraction. In Journal of the American Chemical Society (Vol. 124, Issue 31, pp. 9074-9082). https://doi.org/10.1021/ja0257319

17. Pan, M., Zhou, X., \& Chen, M. (2013). Cellulose nanowhiskers isolation and properties from acid hydrolysis combined with high pressure homogenization. BioResources, 8(1), 933-943. https://doi.org/10.15376/biores.8.1.933-943

18. Poletto, M., Ornaghi Júnior, H. L., \& Zattera, A. J. (2014). Native cellulose: Structure, characterization and thermal properties. Materials, 7(9), 6105-6119. https://doi.org/10.3390/ma7096105

19. Schwanninger, M., Rodrigues, J. C., Pereira, H., \& Hinterstoisser, B. (2004). Effects of short-time vibratory ball milling on the shape of FT-IR spectra of wood and cellulose. Vibrational Spectroscopy, 36(1), 23-40. https://doi.org/10.1016/j.vibspec.2004.02.003

20. Segal, L., Creely, J. J., Martin, A. E., \& Conrad, C. M. (1959). An Empirical Method for Estimating the Degree of Crystallinity of Native Cellulose Using the X-Ray Diffractometer. Textile Research Journal, 29(10), 786-794. https://doi.org/10.1177/004051755902901003 
Figures
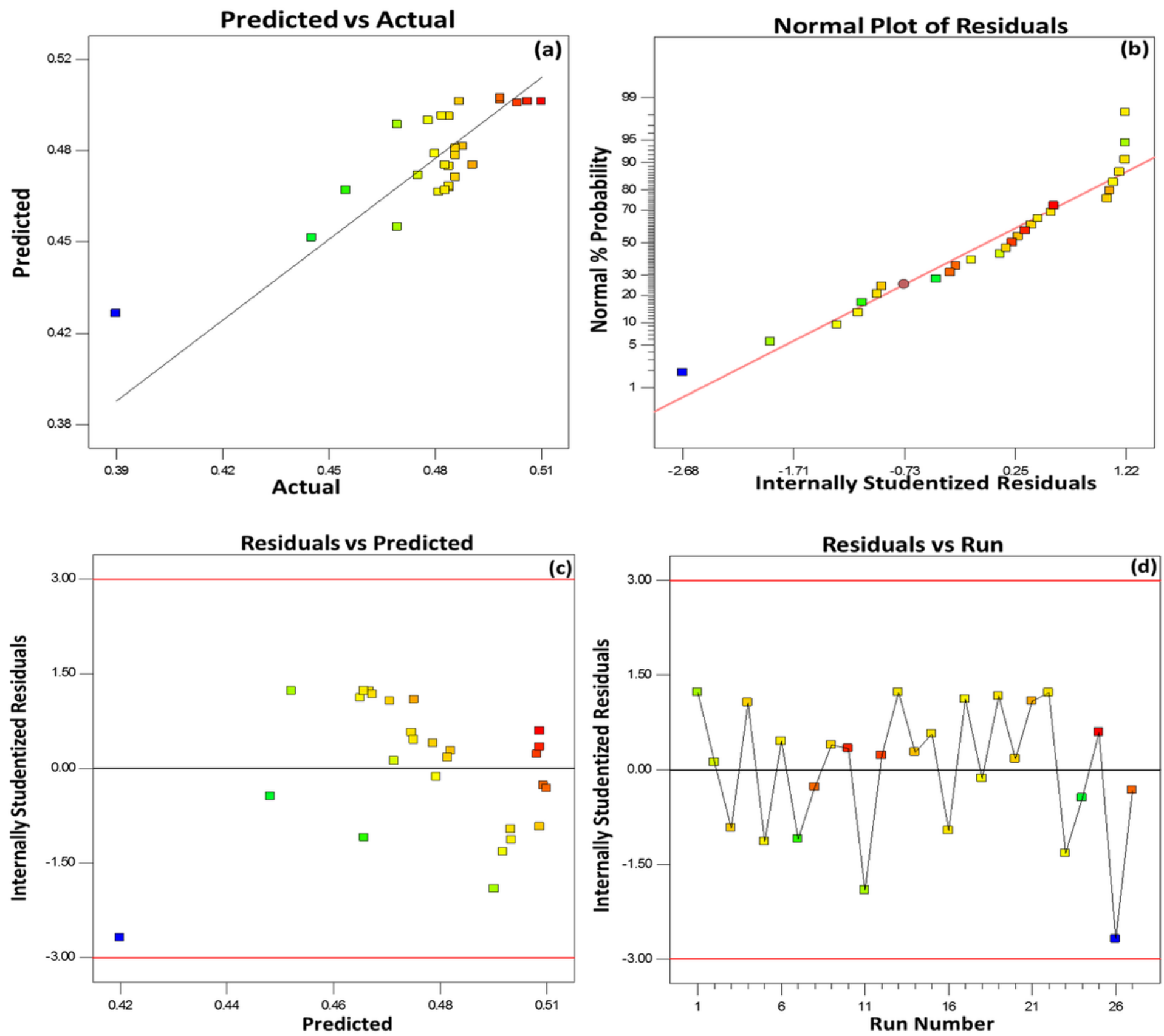

Figure 1

a. Actual vs. predicted values of $\mathrm{TCl}$ of cellulose powders b. to d. Diagnostic Plots of Model 

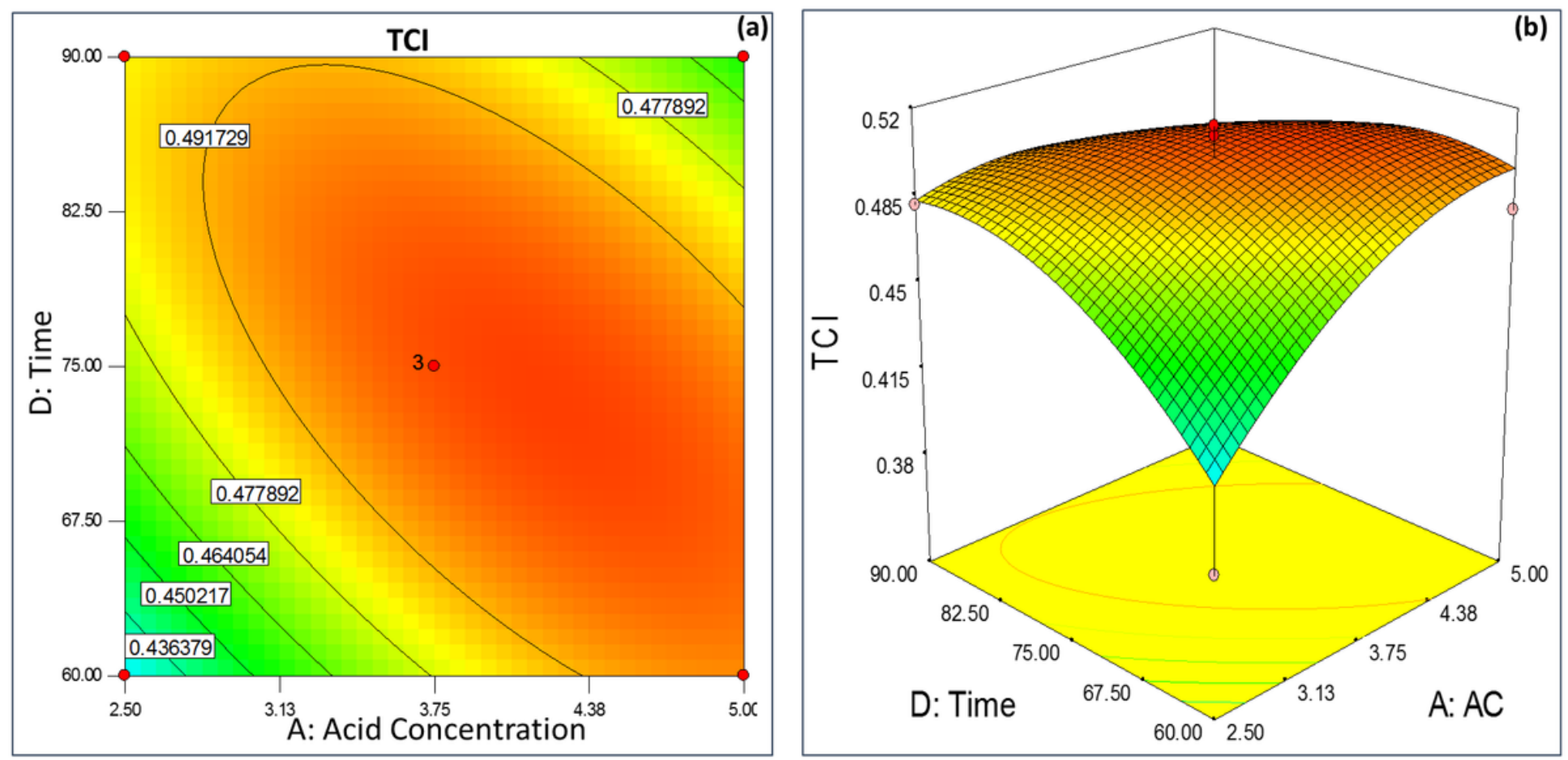

Figure 2

a. Contour and b. 3D Surface plot: simultaneous variation of significant term-AD from table 6 with the response
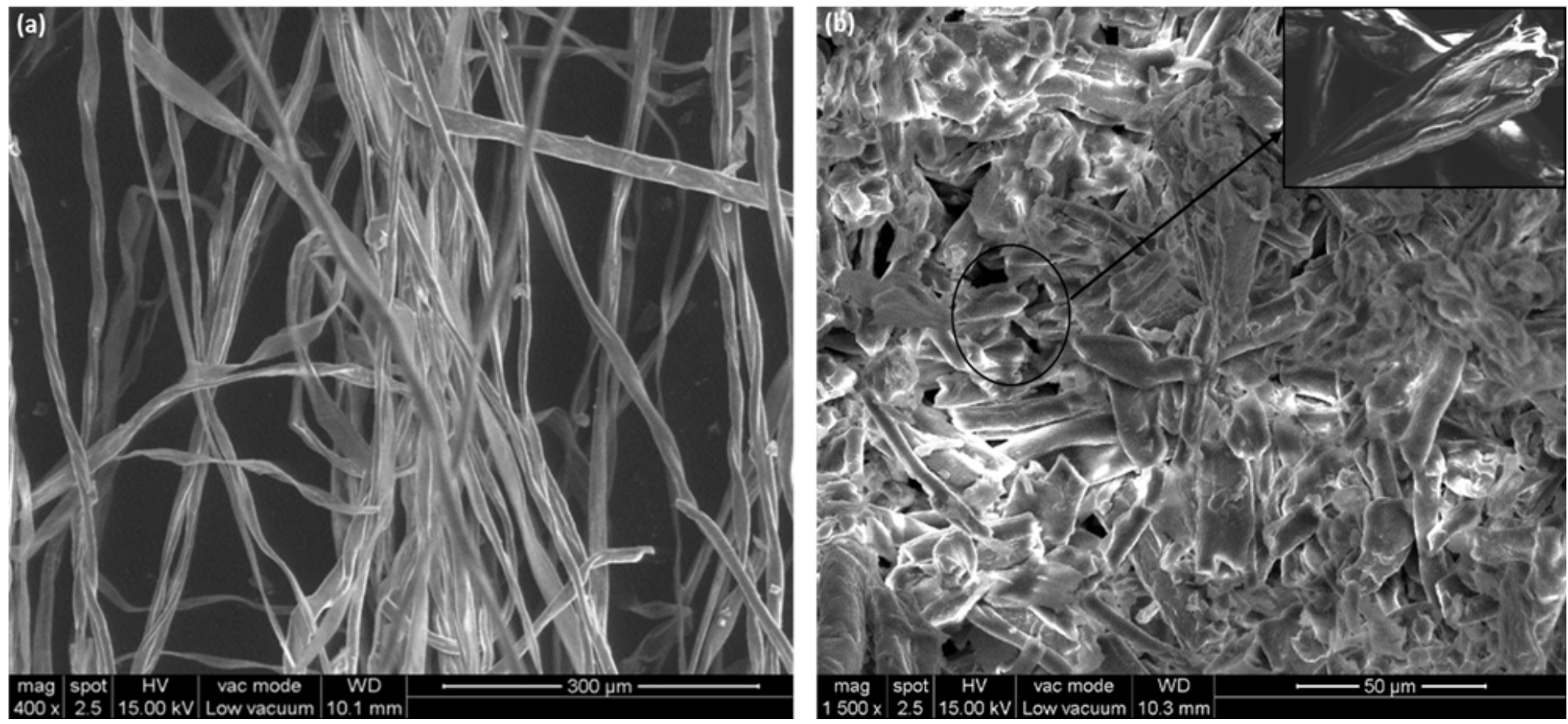

Figure 3

FESEM Micrographs of (a) WCF and (b) MTCI 

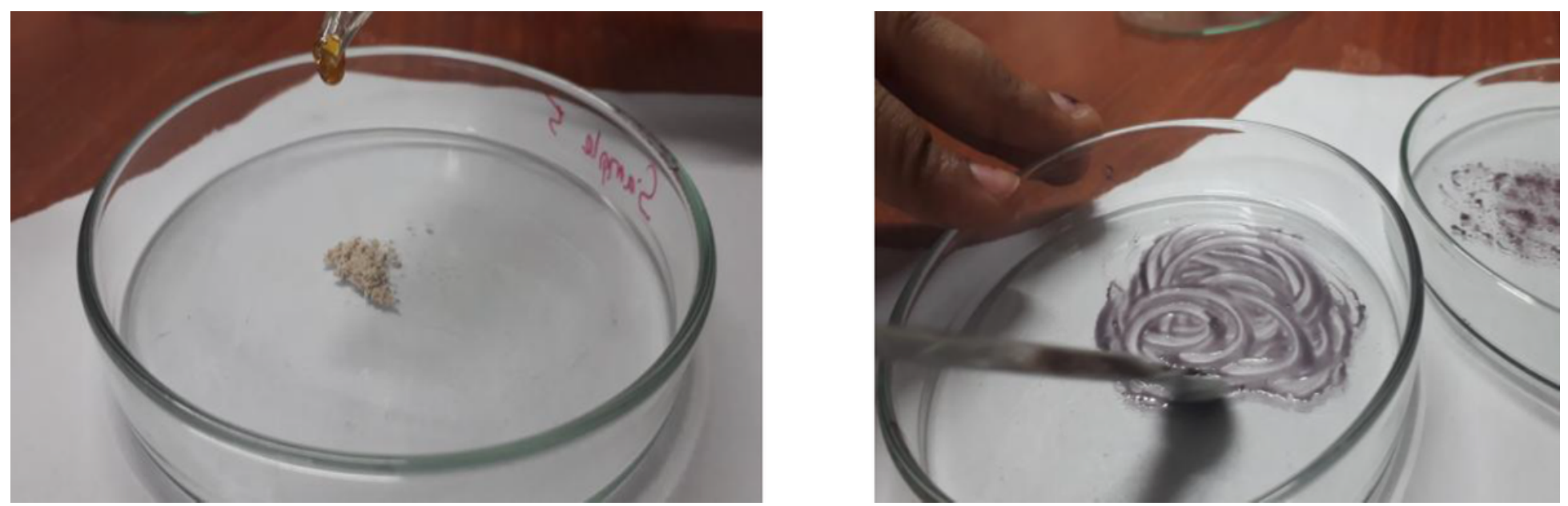

\section{Figure 4}

Colour Identification Test of Cellulose Powders
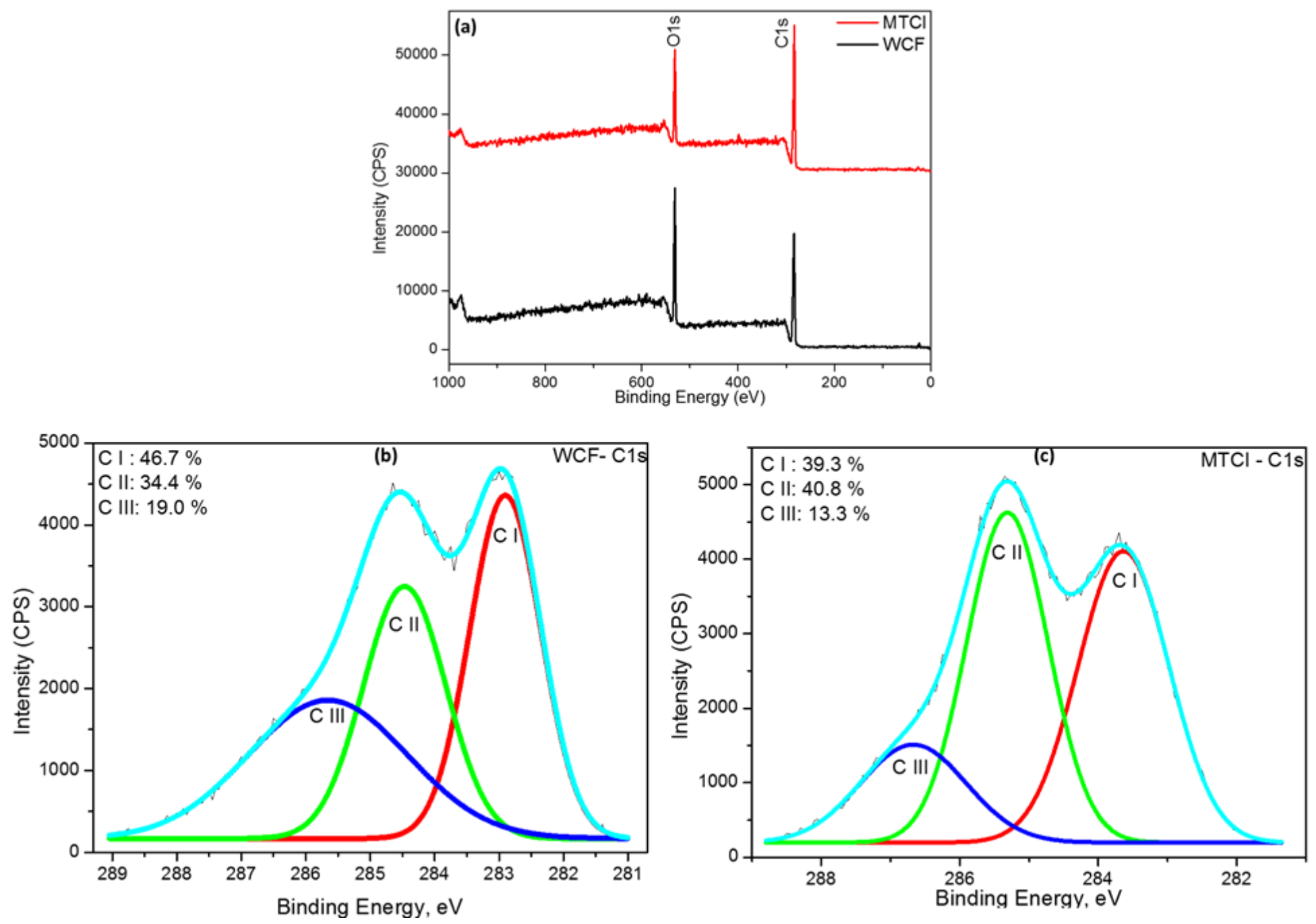

Figure 5

XPS (a) Comparison of Wide Scan Spectra of WCF and MTCl and Deconvoluted C1s High Resolution Spectra of (b) WCF and (c) MTCl 


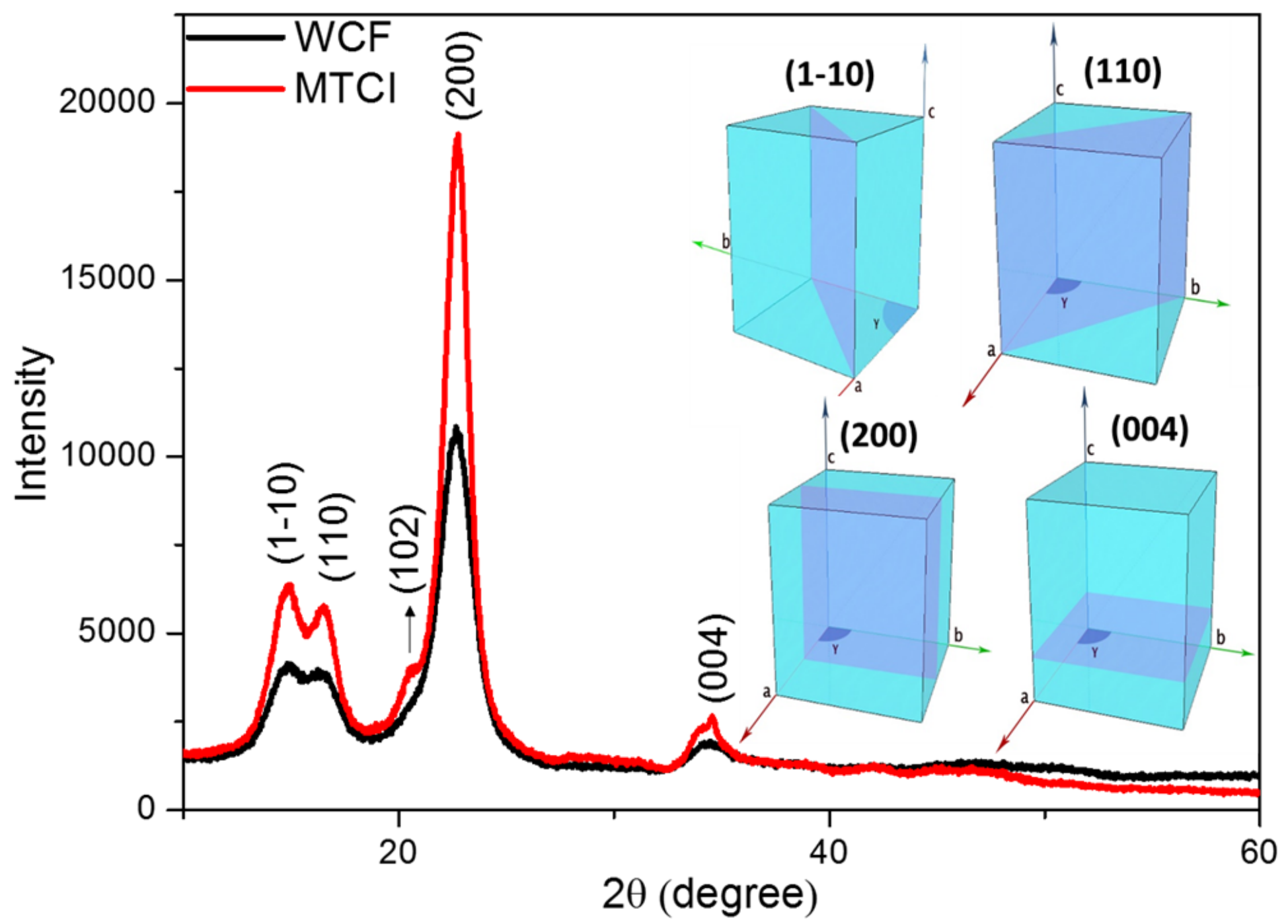

Figure 6

XRD diffraction pattern of WCF and MTCI. Inset- Planes corresponding to peaks in cellulose I $\beta$ unit cell 


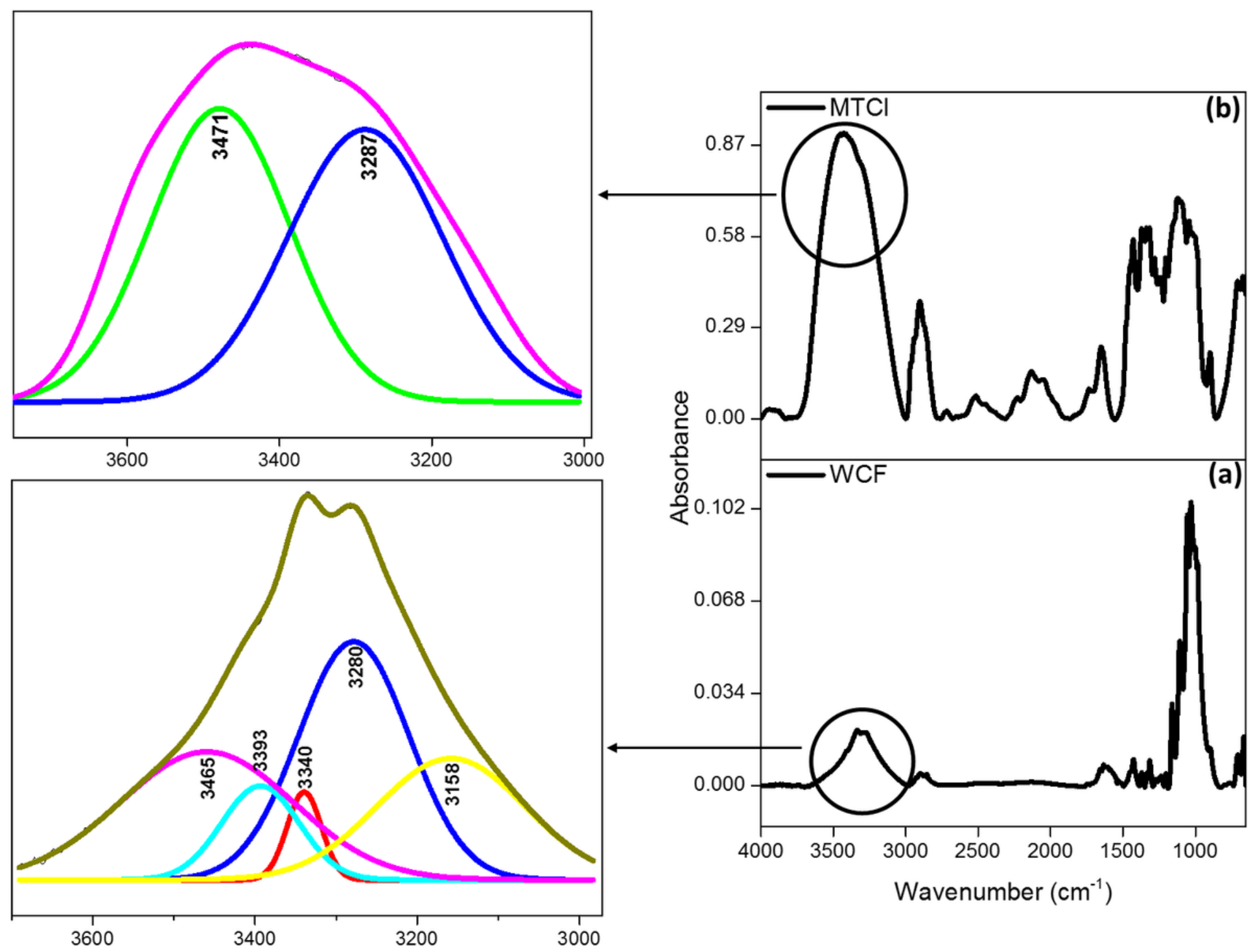

Figure 7

FTIR spectra a.WCF before hydrolysis b. MTCl after hydrolysis
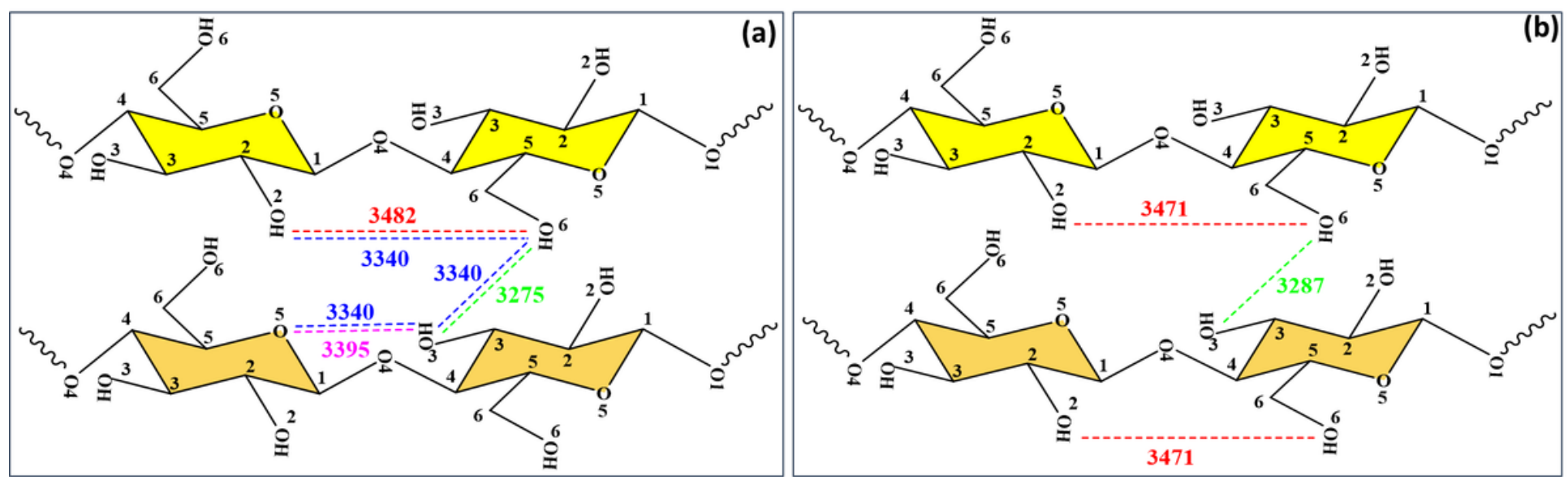

Figure 8

Structure of (a) WCF before hydrolysis and (b) MTCl after hydrolysis 

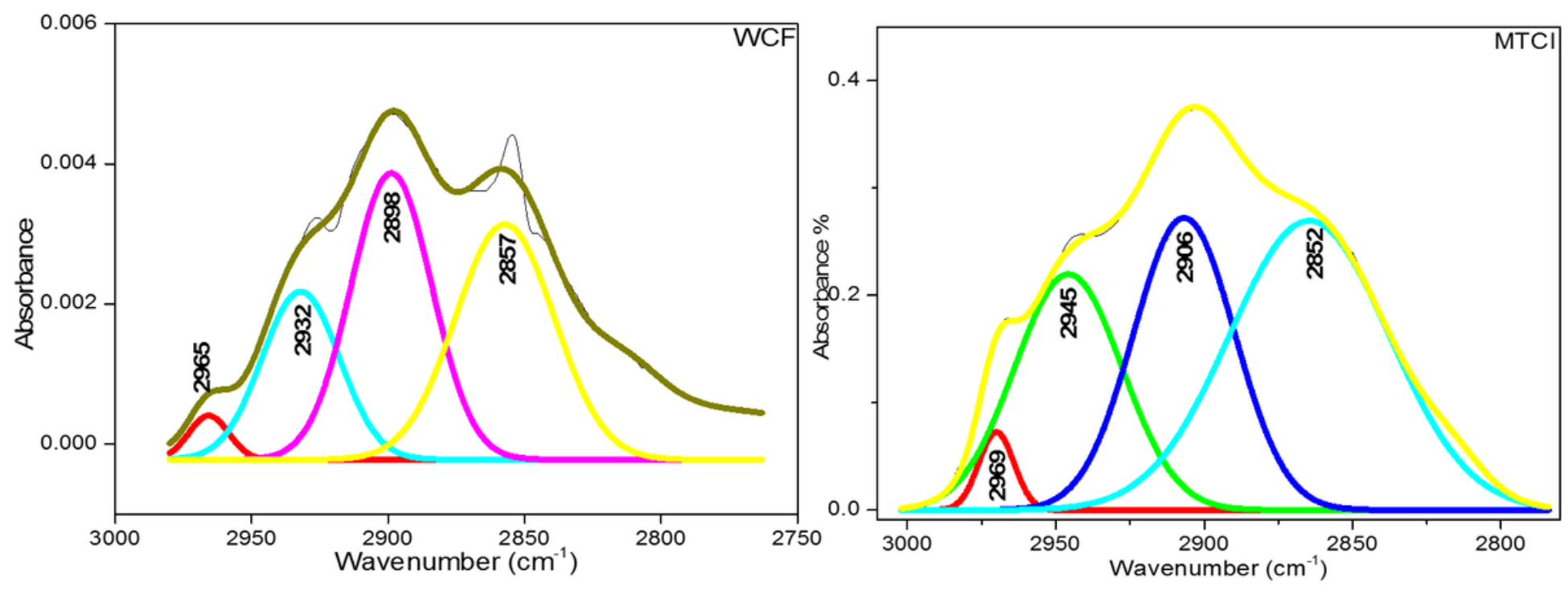

Figure 9

FTIR spectra of WCF and $\mathrm{MTCl}$ in $3000-2800 \mathrm{~cm}-1$ region 